\title{
Current Elements Regarding Risk Management in Insurance Companies
}

\author{
Ciprian Matis \\ ciprian.matis@econ.ubbcluj.ro \\ Babes-Bolyai University, Cluj Napoca, Romania
}

\begin{abstract}
Contemporary approaches regarding insurance risks are extremely dynamic, the more so considering that we are dealing with a complex field from the point of view of risks that one wishes to have covered as well as the multitude of insurance packages offered by insurance companies. Thus we can state that the specialized literature endeavors and succeeds in dealing with a field that is in no way easy to approach. The globalization of the insurance industry provides management with mechanisms for the proper evaluation and handling of risks, to reduce them to limits that are acceptable and supported financially by insurance companies. The present study proposes to analyze risk management from the point of view of the European Directives with respect to data protection and the risks that are generated by not respecting the regulatory unitary framework and the Standard regarding Information technology-Security Techniques Information security risk management. In this sense, in the process of evaluating the risks that insurance distributors are subjected to, we have exemplified the method for evaluating risks by identifying threats, vulnerabilities and the impact on the companies' financials.
\end{abstract}

Key words: risk management, risk evaluation, threats, vulnerabilities

JEL codes: G22, M11

\section{Introduction}

The field that was chosen for research is one that is extensively dealt with both internationally and nationally, being considered highly important.

The domain does not yet discuss a complete solution regarding insurance risks, solutions that might keep pace with such a dynamic field. Solutions are adopted that are conceptualized at an international level, regionally applied but which can suffer qualitative improvements only by thoroughly knowing the particularities of the market in which actions are conducted with respect to the existing cultures, customs and needs;

The creation of value or the economic optimization of insurance services requires some particular attention and clear management strategies in risk management, which may lead to such challenges. In this sense, management within this field can exist regardless but not actively or that might not have the capacity to be compatible with the present tendencies within the field. Existing within an economic market, it is paramount to benefit from financial resources. Answering to market requirements in a timely fashion and knowing how to manage associated risks is the sure-fired path towards economic efficiency;

In addition, implementing the EU Directives, when distributing insurances, has lead to significant modifications in managing the risk levels of companies. The directive sought to harmonize the activities and management of risks towards coherent dispositions with the right of the European Union.

Considering that the most important component in the ability of insurers to handle the unpredictable is the function of risk management, we consider it extremely opportune for study. At this level the ability to anticipate, to develop strategies or to identify specific needs manifest themselves, all these leading to competitive advantages. The creation of a risk community that can take on and apply the principle of mutuality when dealing with damages, that can permit the uninterrupted functioning of the insurance mechanism and to confer psychological comfort to 
the members of a company has and will always have the necessary premises to develop fruitful directions for research. The chosen scientific endeavor automatically impresses an involuntary interest given the extended area of interest that this field of study enjoys.

\section{Methodology}

Starting from the premise of the importance of the scientific endeavor, we may reflect upon the following: the richest economies, which benefit from stability, focuses the most developed segment of insurance upon those places where economic life cannot be drawn under any circumstances without this segment and where protection against risk intuitively implies an understanding that increases exponentially. As a barometer for economic progress, this dynamic and complex field is one which will always draw heightened interest from any member of society. The research that is at the basis for the present article entitled Current Elements regarding Risk Management in Insurance Companies includes both types of scientific research, namely: fundamental scientific research and applied, empirical scientific research. We considered both to be useful and necessary in reaching the objective established above, considering the fact that, by applying them together, the field of study can be covered in its entirety, since each type of research takes from the other what it needs (Ronen and Yaari, 2008:289), they having different ends and logistics.

Identifying, analyzing and evaluating risks necessitates that we take into consideration potential operational problems. For evaluating risk we used the Risk Matrix, starting from the probability that an undesired event might occur within the insurance company.

In order to identify the risk factors, the threats were determined and for each threat we have identified existing vulnerabilities,

Company management is responsible for adopting financial and human measures in order to frame the risks associated within tolerated limits (residual risk).

\section{Risk management - priority objective for insurance societies}

The specialized literature in the field of management is vast; the range of points of view has led many researchers to include the concept of management in certain schools based on the nature of concepts, methods and managerial functions.

Thus we recall the classification done by Ilieș et al.(2009) in: the classic school (universal), the school of human relations (behaviorism), the social systems school (systemic) and the quantitative doctrine or Turcu et al. (2008)in the four categories: classic school, psychological school, quantitative school and systemic school.

Zorlentan et al considers that apart from the aforementioned schools there are a current, a group of managers, consultants and $21^{\text {st }}$ century researchers, that have established the contextual school that is contemporary to the systemic school that is based on the premise that there is no recipe for success in management, rejecting the notion of formulating leadership principles, methods and techniques that are universally valid.

The classic school represented by Taylor and Fayol, followed by a multitude of researchers stands at the basis of research in management, with a focus on the organizational function. F.W. Taylor, considered the founder of the science of management, in his paper "The Principles of Scientific Management"(1911) shows how "the scientific management system implies a complete revolution of the morale of workers and at the same time a revolution of the morale of management", identifying the fundamental principles of management as they are successfully used today in the management strategy of large companies (Division of labor, authority and responsibility, discipline, order, equity, initiative, stability, balance, team spirit, command unit, the unit that subordinates individual interests to the general ones, payment, establishment of hierarchy).

H. Emeson in his research focused in principle on empirical and theoretical analysis of political forces when making regulatory decisions.

From a methodological standpoint this first school plays an important contribution in defining the science of management, naming functions and the elaboration of some scientific principles adopted in future research. But the contributions are oriented more towards 
organizational functions and productions and less so towards human resources.

The second category of researchers belong to the psychological school or the school of human relations, which stress upon human resources considering the fact that people and their behavior constitutes the essence of management, establishing a set of sociological and psychological principles and methods that can positively capitalize upon human potential. This current favors concepts such as: system of values, leadership, organizational culture, individual behavior, group study, etc. The theories regarding motivation, management style, participatory management are developed in order to stimulate and motivate human resources.

The quantitative school is based on mathematics and statistics which permit the calculation of certain performance indicators used by managers in making decisions. Research focuses on applying methods for statistical and mathematical analysis in the activities of production, organization, prediction, which confers efficiency to management.

The important representatives of this current are J. Starr, A Kauffman, F. Goronzy, C. Afanisiev, who use statistical and mathematical concepts and methods such as: graph theory, linear programming, combination analysis etc, for functions such as prediction, organization, research, development and commercial.

Drucker, H. Mintzberg, M. Porter, J. Child, H.A. Simon, C. Bernard, etc. The Systemic school, a newer concept that focuses on the interdisciplinary nature of management. When we speak of the systemic school, we refer to Herbert Simon who, in his work Administrative Behaviour (1997) analyzes the process in which decisions take shape, as a rational choice between two or more variants, concluding that the choice depends on the experience and intuition of the manager. The theories developed by him show how efficient decisions also include a non-rational part that is the result of the manager's intuition.

Peter F. Drucker is known for his work The Practice of Management (1954) in which he develops the MBO (Management by Objectives) system, a participatory and democratic style of management, according to which reaching organizational goals is possible not by issuing orders and instructions, but by insuring the cooperation and participation of all employees. In the author's opinion, goals need to be operational, to permit the distribution of tasks across all organizational levels, while at the same time they need to be motivated by people. We can affirm that $\mathrm{MBO}$ is not only a style of management, but that it represents a philosophy of work, selfcontrol, change and responsibility. Peter F. Drucker's influence is also seen on the management of Japanese companies, his ideas having been successfully accepted also by American and European companies.

Also worthy of remembrance for the field of management are the works Concept of the Corporation; The Effective Executive; Management: Tasks, Responsibilities, Practices; Managing in Turbulent Times. In Drucker's opinion, management makes up the difference between success and failure in business by establishing the goals of the organization, the motivation and overall communication of the organization, the establishment of methods for measuring performance and the development of people's abilities and performance.

We may consider that the systemic school is a synthesis of the other previously mentioned currents, at the basis of which is the concept of a complex system with all the connections between production, social and economic activities, as well as those of the environment.

The contextual school, considered by many researchers to be contemporary to the scholastic school, appeared as a result of managerial practice, some managers considering that the principles of management cannot be applied in equal manner, as each particular situation necessitates a different involvement on the manager's part. Thus a group of managers and researchers set up the contextual school, having considered that each company must be run by those methods and instruments that are compatible with the respective situation. This current proposes that managers apply a participatory style of management adapted to the direction in which the company develops. This management style, when put into practice in various contexts, can have diametrically opposed consequences. 
We may conclude that the Classic school represented by Taylor and Fayol, followed by a multitude of researchers, is the one which established the foundation of the science of management, focusing on organization, followed by the psychological school that stresses upon the human aspect, considering that people and their behavior constitute the essence of management. These have made possible the development of the quantitative school, based on mathematical and statistical models which permit for the calculation of performance indicators used by managers in this act of leading. All these elements are then used by the systemic school, a new concept that looks at the interdisciplinary nature of management, from which the contextual school developed, which in turn maintains that each particular situation implies intervention on behalf of the managers.

In our opinion, in order to obtain performance in management in the present state of things, characterized by a globalization of the market, the technological explosion of information and audio-visual businesses, the steep competition and the creation of pillars of power (NAFTA, EU and Asia SE), what is important is to have a global view of the process of risk management as a strategic concept anchored in today's reality.

In this sense, we consider that each company has to apply the principles of management by utilizing the methods, resources, information and means that might endure the realization of their strategic objectives.

When speaking of risk, what is important to remember their classification, as they appear in the Directive regarding the Solvency of Insurance and Reinsurance Companies (Directive /EC Solvency II, 2009), respectively

$>$ Risks that manifest themselves at the level of the insurance companies: risk of underwriting, credit risk, reinsurance risk, operational risk, investment risk, liquidation risk, risk of lacking reserves.

$>$ Risks that manifest themselves at the level of the entire insurance industry: jurisdictional risk, legislative risk and market risk.

$>$ Systemic risks that manifest themselves at the level of the economy as a whole: decrease in value across the investment market, environment changes, socio-political changes, inflation rates, interest rates, technological changes.

Figure 1 Classifying risk according to the EU / Solvency II Directive

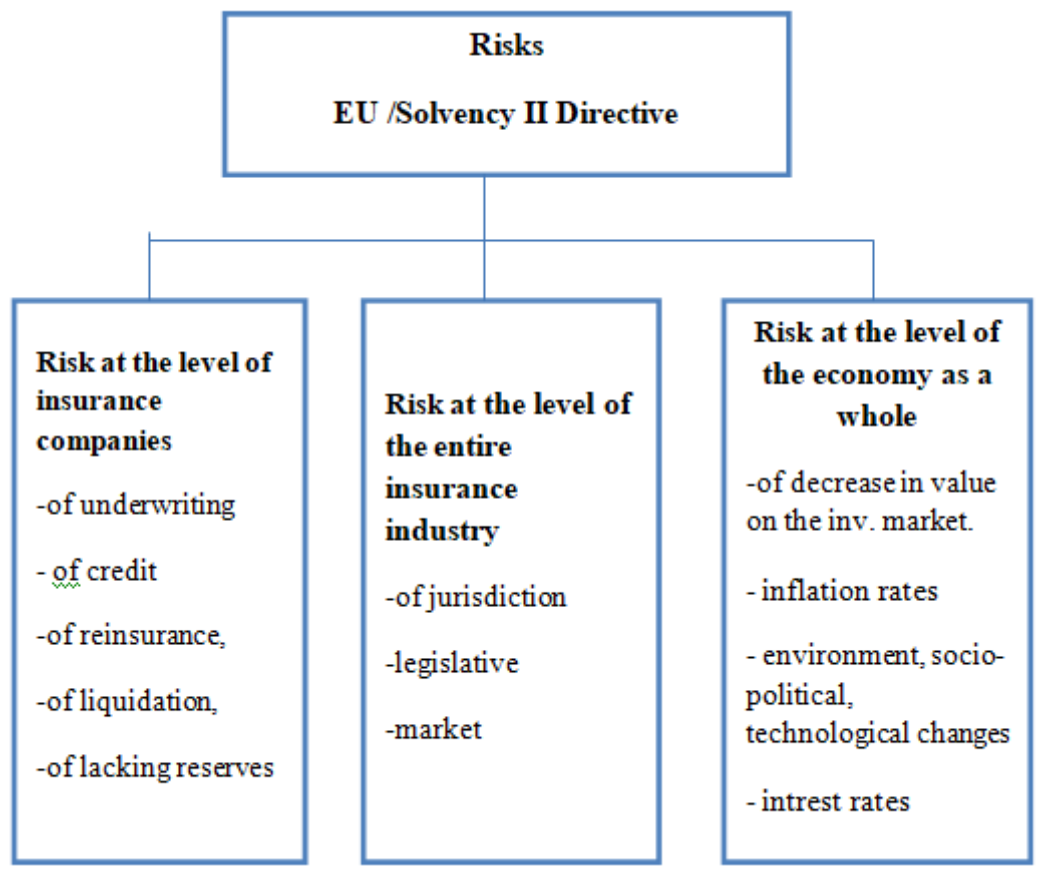

Source: the author 
The directive regarding the means of calculating solvency and the standards for risk management, Solvency II (Directive 2009/138/EC of the European Parliament and of the Council) has a range of applicability over all insurance and reinsurance companies within the European Union. These must be ready to define for themselves and to implement the strategies and models of risk management, the corporative governance, systems of distribution in such a way that trust in the insurance industry might be established. The objectives of Solvency II have as a goal the protection of those insured and of the shareholders of insurance companies by establishing a system of solvency that would take into consideration all the risks that insurance companies belonging to countries within the European Union are exposed to. We consider that the implementation of the provisions of the directive would lead to streamlining and securing the insurance and reinsurance market, to protection for those insured, the stimulation of a rise in competition and the development of a surveillance system that is efficient and adapted to the European legislation. An analysis conducted at the level of the European Union by The Muller Group (The Solvency of Insurance Undertakings account) shows that operational risks respectively incompetent or insufficiently experienced management, fraud, transactions within groups followed by risks tied to underwritings through undervalued underwritings, reinsurance, high operational costs and risks determined by investments are the ones that have determined most of the cases of insolvency for insurers.

However it isn't enough to know and be able to classify these risks, as they need to be quantified, by determining their level of acceptability, managed, understood and controlled or transferred. Thus, when we refer to management in the field of insurance we have in mind the particularities that are determined by the influence of insurance risks and the need for analyzing and transferring risk to the reinsurer.

It is important to analyze risk management starting from the classification of risks as done by the European Directives and to establish strategies, policies and procedures with respect to responsibilities at the level of making decisions taking into consideration the multitude and variety of these risks.

We consider that risk management has the task of analyzing and quantifying the probability and impact of risk-generating events, the classification and framing within contracts taking into consideration potential responsibilities and future losses due to the occurrence of the considered risks. Through the signed contracts, the insured risk, its nature and size, as well as the promise for financial recompense for any possible future losses are determined.

Dealing with risk should not be made absolute at the level of legal regulations but at the level of the requirements and interests of the insured, based on the adapted law.

In order to put into practice these requirements we have conducted within a company an evaluation of the operational risks, grouped by category, respectively: people, processed, information systems and outside environment. Considering the large number of threats and vulnerabilities at the level of companies, we have considered it important for us to shift our research towards risks regarding the protection of personal data. Another consideration for which we have paused upon this risk sector is the enormous volume of personal data that a company and its insurance intermediaries (for health insurance, life insurance, AUTO insurance, travel insurance, private pensions etc.). For each category we have identified the risk factors, comprising a list of threats and for each threat the vulnerabilities were identified. 
Figure 2 Management activities according to the framework of risk categories

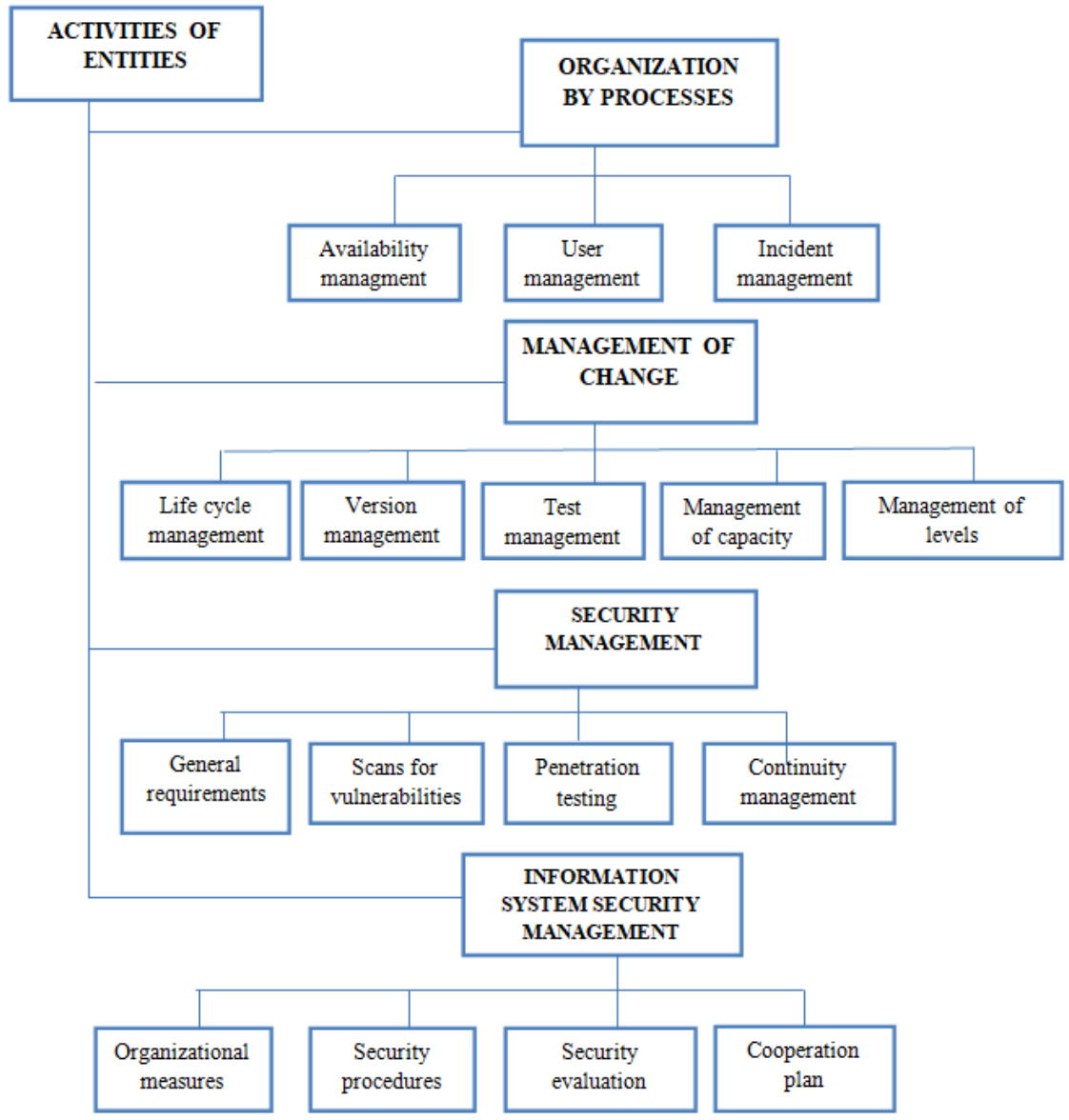

Source: the author

For calculating the risk, we have determined

- First of all the probability that an undesired event will occur, based on a matrix that evaluates vulnerability and threat

Table 1 Evaluating the probability that an undesired event will occur

\begin{tabular}{|l|l|l|l|}
\hline $\begin{array}{c}\text { THE PROBABILITY THAT AN } \\
\text { UNDESIRED EVENT WILL } \\
\text { OCCUR }\end{array}$ & \multicolumn{3}{c|}{ THREAT } \\
\hline VULNERABILITY & Small(0) & Average(1) & High(2) \\
\hline Small(0) & V.Small(0) & Small(1) & Average(2) \\
\hline Average(1) & Small(1) & Average(1) & High(3) \\
\hline High(2) & Average(2) & High (3) & V. High (4) \\
\hline
\end{tabular}

Source: the author

-In the next stage we have determined the impact on business of each undesired event and we have evaluated the risks and associated levels for each undesired event (a matrix for risk level was realized) 
Table 2 Qualitative risk analysis - risk matrix

\begin{tabular}{|c|c|c|c|c|c|}
\hline RISK MATRIX & \multicolumn{5}{|c|}{$\begin{array}{l}\text { The probability that an undesired event will occur (Threat } x \\
\text { Vulnerability) }\end{array}$} \\
\hline $\begin{array}{l}\text { Destructive impact of the event } \\
\text { on the business }\end{array}$ & V.Small(0) & Small(1) & Average(2) & High (3) & V. High (4) \\
\hline Very Small (0) & $\begin{array}{ll}\text { Small } & \text { Risk } \\
(0) & \\
\end{array}$ & $\begin{array}{ll}\text { Small risk } \\
\text { (1) }\end{array}$ & Small Risk (2) & $\begin{array}{l}\text { Average } \\
\text { Risk (3) }\end{array}$ & Average Risk (4) \\
\hline Small (1) & $\begin{array}{l}\text { Small } \quad \text { Risk } \\
\text { (1) }\end{array}$ & $\begin{array}{l}\text { Small Risk } \\
\text { (2) }\end{array}$ & $\begin{array}{l}\text { Average Risk } \\
\text { (3) }\end{array}$ & $\begin{array}{l}\text { Average } \\
\text { Risk (4) }\end{array}$ & $\mathrm{sk}(5)$ \\
\hline Average (2) & $\begin{array}{l}\text { Small } \quad \text { Risk } \\
\text { (2) }\end{array}$ & $\begin{array}{l}\text { Average } \\
\text { Risk (3) }\end{array}$ & $\begin{array}{l}\text { Average Risk } \\
\text { (4) }\end{array}$ & $\begin{array}{l}\text { Average } \\
\text { Risk (5) }\end{array}$ & High Risk (6) \\
\hline High (3) & $\begin{array}{l}\text { Average Risk } \\
\text { (3) }\end{array}$ & $\begin{array}{l}\text { Average } \\
\text { Risk (4) }\end{array}$ & $\begin{array}{l}\text { Average Risk } \\
\text { (5) }\end{array}$ & $\begin{array}{l}\text { High Risk } \\
(6)\end{array}$ & High Risk (7) \\
\hline Very High (4) & $\begin{array}{l}\text { Average Risk } \\
\text { (4) }\end{array}$ & $\begin{array}{l}\text { Average } \\
\text { Risk (5) }\end{array}$ & High Risk (6) & $\begin{array}{l}\text { High Risk } \\
\text { (7) }\end{array}$ & High Risk (8) \\
\hline
\end{tabular}

Source: the author

In continuing the study we have established the measures of control and tolerance limits (residual risk), which we can present

Figure 3 Modes of risk treatment

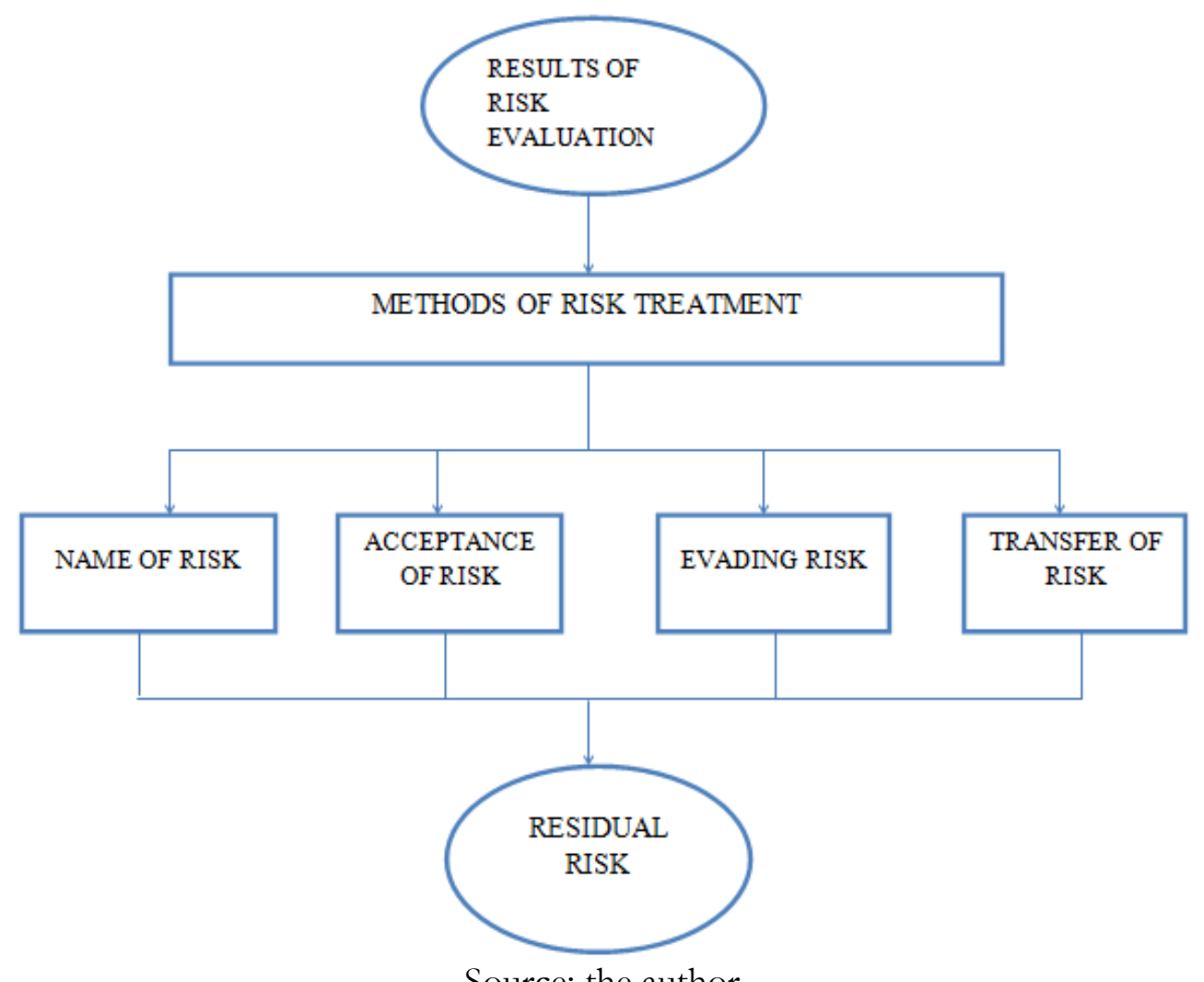

Source: the author

As shown by the results from the above figure, the first measure taken by management is the diminishing of risk so that the residual risk may be accepted by management. If the risk levels are in accordance with the policies and strategy of the company, further supervision may be accepted in order to maintain as much as possible the residual risk. If the risks necessitate great financial and human resources, the activities that generate them can be removed. Insurance companies most often transfer the risk to a reinsurer or to third parties that are willing to take it. 
In order to fit within established tolerance limits, management has to impose measures regarding the business model, adjustments to the organizational structure, revision of processes, procedures, interior regulations, employment contracts, service contracts, etc. All these measures needed for the elimination or reduction of vulnerabilities, threats and the impact on business are analyzed at the management level and necessary adjustments are done to organizational structures, revision of processes, procedures etc. and financial resources are necessary for the handling of risks.

\section{Conclusions}

We consider that such studies are absolutely necessary in companies that distribute insurance products, considering the large volume of personal data that is processed (AUTO insurance, goods insurance, professional insurance, etc.) as well as the processing of special character data (evaluating health conditions for life and health insurance, data of minors for travel insurers or insurance policies for income etc.)

An efficient impact study will allow for management to identify and remediate problems in an incipient study, reducing the risks and costs associated with these. In addition, the steps taken would enhance in the company the degree of awareness of problems related to the confidentiality and protection of the information.

We can affirm that risk management within insurance companies consists not only of the efficiency of activities by determining the insured risks, across levels of insurance, which should be understood, quantified, analyzed in order to make the best decisions when covering damages, establishing bonuses, periods of insurance and technical reserves but also by determining the operational risks that can affect their activities, both at a reputational as well as financial level. The management of insurance companies at the highest level is responsible for the identification, prevention and reduction of the operational risks generated by the current activities and the adopting of financial and human measures needed in order to frame the tolerance limits of the risks.

We consider that aligning oneself to new international standards impose a new type of management capable of organizing and administering the risks, technology, databases and last but not least to consolidate the clientele in raising awareness of the need for protection and choice of insurance products based on their requirements but also to anticipate new specific needs.

From the point of view of, insurability has no absolute limits, one should not analyze only those aspects of a technical and financial nature, but also some aspects that are determined by the potential operational risks determined by processes, computer systems, human resources and external factors, which determine that some previously uncertain risks to affect the company's activity.

\section{References}

1. Cooper, R., Frank, G. L., (2005), The Highly Troubled Ethical Environment of the Life Insurance Industry: Has It Changed Significantly from the Last Decade and If so, Why?

2. Drucker, P., Managing the Non- Profit Organization, Harper - Collins, New York, (1990); The Pension Fund Revolution, Harper \& Row Publishers, 1976; The New Society, Harper \& Row Publishers, 1950

3. Ronen, J. and Yaari, V. (2008), Earnings Management: Emerging Insights in Theory, Practice and Research, Hardcover, Springer Series in Accounting Scholarship, vol. 3, p. 289

4. Ilieș, L.,Mortan M.,Lungescu D.,Lazăr I.,Popa M., Vereș V., (2009), Management. Cluj-Napoca, Risoprint, p. 39

5. Simon, H., (1997), Administrative Behaviour: A Study of Decision- Making Processes in Administrative Organization, 4th edition, The Free Press

6. Zorlentan T. et.al., Managementul organizatiei, Editura Economica, Bucuresti, 1998, p. 44-45 
International Conference "Risk in Contemporary Economy" ISSN-L 2067-0532 ISSN online 2344-5386 XX $^{\text {th }}$ Edition, 2019, Galati, Romania,

"Dunarea de Jos" University of Galati, Romania - Faculty of Economics and Business Administration

\section{Other sources}

1.Directive / EC Solvency II, 2009)

2. UE Regualtion 2016/679

3. UE Directive $2016 / 1148$

4. ISO 31000

5. ISO/IEC 27005 